\title{
Medication Regimens for Managing Acute Asthma
}

\author{
Diego J Maselli MD and Jay I Peters MD
}

\author{
Introduction \\ Definition and Importance of Asthma Exacerbations \\ Patients at Risk for Severe Asthma Exacerbations \\ Diagnostic Considerations \\ Pharmacotherapy for Asthma Exacerbations \\ Short-Acting $\boldsymbol{\beta}_{2}$ Agonists \\ Short-Acting Muscarinic Antagonists \\ Systemic Corticosteroids \\ Methylxanthines \\ Magnesium Sulfate \\ Helium-Oxygen Therapy \\ Epinephrine \\ Patient-initiated Therapy \\ Treatment in the Out-Patient Setting \\ Therapy in the Emergency Department \\ Management of Patients Admitted to the Hospital: Wards and ICU Care \\ Management of Status Asthmaticus in the ICU \\ Unproved Alternate Therapy in Status Asthmaticus \\ Postdischarge Therapy and Importance of an Action Plan \\ Summary
}

\begin{abstract}
Asthma exacerbation is defined as a progressive increase in symptoms of shortness of breath, cough, or wheezing sufficient to require a change in therapy. After ruling out diagnoses that mimic an asthma exacerbation, therapy should be initiated. Short-acting $\beta_{2}$ agonists and short-acting muscarinic antagonists are effective as bronchodilators for asthma in the acute setting. Systemic corticosteroids to reduce airway inflammation continue to be the mainstay therapy for asthma exacerbations, and, unless there is a contraindication, the oral route is favored. Based on the current evidence, nebulized magnesium should not be routinely used in acute asthma. The evidence favors the use of intravenous magnesium sulfate in selected cases, particularly in severe exacerbations. Methylxanthines have a minimum role as therapy for asthma exacerbations but may be considered in refractory cases of status asthmaticus with careful monitoring of toxicity. Current guidelines recommend the use of helium-oxygen mixtures in patients who do not respond to standard therapies or those with severe disease. Key words: asthma exacerbation; asthma therapy; bronchodilators; severe asthma. [Respir Care 2018;63(6):783-796. (C) 2018 Daedalus Enterprises]
\end{abstract}

\section{Introduction}

Asthma is one of the most common chronic respiratory conditions in children and adults, and is associated with significant morbidity and health-care expenditure, which is driven in large part by asthma exacerbations. These events have significant consequences in asthma quality of life and reduced school and/or workdays, and in the cost of health care. Appropriate evidence-based therapy for exacerbations is key in an attempt to reduce the burden of these acute episodes and help in the rapid recovery of these patients. Over the past several decades, there has been an increase in the understanding of which therapies are effective in the management of acute asthma. Both systemic corticosteroids and bronchodilators continue to be the cornerstone for therapy in acute asthma, but other therapies, 
such as magnesium sulfate and helium-oxygen mixtures, may have a role, particularly in severe asthma. Advances have been made in determining the best method of delivery and frequency of bronchodilators, and the implementation of patient-initiated therapy has been linked to improved asthma control. The treatment for acute asthma varies from the out-patient setting to the ICU. In patients with severe or life-threatening exacerbations, various therapeutic strategies have been studied to improve outcomes. The purpose of this review is to describe the treatment options for acute asthma and the clinical evidence behind these interventions.

\section{Definition and Importance of Asthma Exacerbations}

The long-term goals for management of asthma are to achieve good control of symptoms, maintain normal activity, and minimize the risk of asthma exacerbation. ${ }^{1}$ However, even with optimal care, approximately $10 \%$ of patients with asthma will experience a major exacerbation that requires oral corticosteroids, an emergency department visit, or hospitalization once a year. ${ }^{2}$

Exacerbations of asthma are defined as a progressive increase in symptoms of shortness of breath, cough, or wheezing sufficient to require a change in therapy. ${ }^{1}$ Usually exacerbations occur in patients with preexisting asthma but can be the first presentation of asthma. Most often, asthma flares or asthma attacks occur as the result of a viral upper respiratory infection, exposure to an allergy, or the result of poor adherence to controller medications.

\section{Patients at Risk for Severe Asthma Exacerbations}

Careful consideration should be carried out in patients with risk factors for severe asthma exacerbations. Patients with exacerbations that led to endotracheal intubation, previous admissions to the ICU, a history of multiple $(\geq 3)$ hospitalizations in the past year or multiple $(\geq 3)$ emergency department visits in the past month, the need of chronic oral corticosteroids use, poor access to health care,

The authors are affiliated with the Department of Medicine, Division of Pulmonary Diseases and Critical Care, UT Health, San Antonio, Texas.

The authors have disclosed no conflicts of interest.

Dr Peters presented a version of this paper at the 56th ResPiratory CARE Journal Conference, Respiratory Medications for COPD and Adult Asthma: Pharmacologic Actions to Clinical Applications, held June 22-23, 2017 in St Petersburg, Florida.

Correspondence: Jay I Peters MD, Department of Medicine, Division of Pulmonary Diseases and Critical Care, 7400 Merton Minter MC 111E, San Antonio, Texas, 78229. E-mail: peters@uthscsa.edu.

DOI: $10.4187 /$ respcare. 05953 and frequent use of rescue inhalers are considered to have increased risk of severe asthma exacerbations and death. Patients with asthma and with these characteristics should be evaluated promptly and treated expeditiously. In addition, a minority of patients with asthma may experience a significant decline in lung function without a change in symptoms. ${ }^{3}$ These "under-perceivers" are at higher risk for near-fatal exacerbations. ${ }^{4}$ This article focuses on the approach to manage exacerbations of asthma.

\section{Diagnostic Considerations}

Before initiating therapy for an exacerbation of asthma, it is important to exclude conditions that may mimic an acute deterioration of asthma. ${ }^{1}$ Patients with COPD may also have similar symptoms during a COPD exacerbation. Patients with COPD are typically older and have a significant history of tobacco exposure. Congestive heart failure is a condition that is also encountered in older individuals and may present acutely with respiratory symptoms, such as dyspnea and wheezing. Patients with congestive heart failure often have a history of other cardiovascular diseases (eg, hypertension), and may have signs and symptoms of volume overload, such as orthopnea, lower extremity edema, and pulmonary edema evidenced on chest radiograph. Other conditions that present with an acute deterioration of respiratory status, including pneumonia, pulmonary embolism, pneumothorax, and acute myocardial infarction, should be considered in all patients.

\section{Pharmacotherapy for Asthma Exacerbations}

\section{Short-Acting $\boldsymbol{\beta}_{2}$ Agonists}

The pathophysiology of asthma involves increased hyper-reactivity that results in airway inflammation and bronchoconstriction. For this reason, a mainstay of therapy for acute asthma involves bronchodilators. The most commonly used bronchodilators in asthma are inhaled $\beta_{2}$ agonists. Activation of $\beta_{2}$ receptor results in stimulation of the adenylyl cyclase, which results in closing of calcium channels and subsequent relaxation of the smooth muscle through inactivation of myosin light-chain kinase and activation myosin light-chain phosphatase. Inhaled $\beta_{2}$ agonists are classified based on the duration of their effect: short-acting $\beta_{2}$ agonists and long-acting $\beta_{2}$ agonists. Albuterol, a short-acting $\beta_{2}$ agonist, is the most widely used bronchodilator for the treatment of acute asthma. It has a half-life of 4-6 h and rapid onset of action. Typical adverse effects include tachycardia, nervousness, tremors, and chest pressure.

Albuterol can be delivered via the inhaled route, administered orally, or administered intravenously. During an asthma exacerbation, the inhaled delivery form is favored 
over the other modalities. During this stage of treatment, albuterol can be delivered through a pressurized metereddose inhaler with a spacer ( 5 puffs followed by 3-5 puffs every $20 \mathrm{~min}$ ) or via nebulization. ${ }^{5}$ Costs may vary from institution to institution, with some institutions using nebulizers more frequently in the initial stages. There is controversy regarding the benefits of continuous versus intermittent inhaled albuterol. A systematic review of 6 studies that included 393 subjects found equivalence of continuous compared with intermittent albuterol during an asthma exacerbation. ${ }^{6}$ Nevertheless, a subsequent meta-analysis of 8 studies that totaled 461 subjects found that continuous treatment with albuterol reduced hospital admissions in subjects with severe asthma who presented to the emergency department and improved lung function compared with intermittent delivery. ${ }^{7}$ For these reasons, it is recommended that patients receive continuous therapy in the earlier stages of therapy, particularly for severe exacerbations, with a change to intermittent dosing at the later stages of therapy and after the patient's symptoms improve. ${ }^{1}$ The addition of intravenous albuterol to an inhaled regimen has not consistently shown benefit and is currently not recommended. ${ }^{8,9}$ Oral preparations of short-acting $\beta_{2}$ agonists, such as salbutamol, are not recommended during an asthma exacerbation because the effects are not superior to inhaled preparations, have a slower onset of action, and have an increased incidence of adverse effects. ${ }^{1,10}$

\section{Short-Acting Muscarinic Antagonists}

Inhaled muscarinic antagonists are bronchodilators frequently used during asthma exacerbations. These medications block the action of acetylcholine on muscarinic receptors and results in a decrease in cyclic guanosine monophosphate and alterations in intracellular calcium concentrations, with subsequent airway smooth-muscle relaxation. Treatment with muscarinic antagonists results in bronchodilation and decreased mucus production. This class of medications is classified into short-acting muscarinic antagonists and long-acting muscarinic antagonists. Ipratropium bromide, a short-acting muscarinic antagonist, was shown to decrease hospitalizations in children and adults with an asthma exacerbation. ${ }^{11,12}$ Combination therapy of ipratropium and a short-acting $\beta_{2}$ agonist results in improvements in lung function compared with short-acting $\beta_{2}$ agonists alone, particularly during severe exacerbations. ${ }^{11-13}$ It is recommended to add ipratropium to the bronchodilator regimen in patients with asthma with a moderate-to-severe exacerbation, especially in the initial stages of treatment. ${ }^{1}$

\section{Systemic Corticosteroids}

Corticosteroids have a pivotal role in the treatment of asthma by reducing airway inflammation. Although asthma corticosteroids are routinely delivered by the inhalation route for stable disease, during an exacerbation, systemic corticosteroids are preferred. Systemic corticosteroids are recommended for all but the mildest asthma exacerbations. Despite considerable debate regarding the mode of delivery, intravenous or intramuscular routes do not provide significant advantages over the oral route. ${ }^{14}$ The oral route is preferred if the patient is able to tolerate taking oral medication and there are no concerns for abnormal intestinal absorption. ${ }^{1}$ The dose that is recommended for an asthma exacerbation is $50 \mathrm{mg}$ of prednisolone (or prednisone) or its equivalent for 5-7 days. ${ }^{1}$ Longer-duration regimens have not been found to be superior. ${ }^{15,16}$

Early administration of systemic corticosteroids has been associated with improved outcomes. ${ }^{17}$ Although written asthma action plans may advocate doubling the dose of inhaled corticosteroids during an exacerbation, a systematic review of 8 randomized controlled trials, which included 1,669 subjects with mild-to-moderate asthma, found no significant reduction in the odds of requiring oral corticosteroids after increasing the dose of inhaled corticosteroids compared with a stable dose. ${ }^{18}$ Despite these findings, other studies found benefits of administering inhaled corticosteroids during the initial presentation of an asthma exacerbation in the emergency department. ${ }^{19}$ For milder exacerbations, early use of high-dose inhaled corticosteroids may be an alternative for oral corticosteroids. ${ }^{19}$

\section{Methylxanthines}

Theophylline and aminophylline, the most widely used methylxanthines in asthma, are nonselective phosphodiesterase inhibitors. Inhibition of this enzyme raises intracellular cyclic adenosine monophosphate, activates protein kinase A, and may have other immunomodulatory effects. In addition, this class of medications can activate, nonselectively, adenosine receptors. ${ }^{20}$ Potential beneficial clinical effects include bronchodilation, improved mucociliary transport, and enhanced diaphragmatic contractility. ${ }^{20}$ These properties make this class of medications an attractive option for the treatment of asthma exacerbations. Aminophylline, which is administered intravenously, has been studied more extensively in this setting. A meta-analysis of 17 studies that explored the effects of adding intravenous aminophylline to inhaled $\beta_{2}$ agonists for the treatment of asthma exacerbations found no benefit with regard to bronchodilation or the risk for hospital admission. ${ }^{21}$ Importantly, compared with placebo, aminophylline was associated with an increased incidence of vomiting and arrhythmias or palpitations. ${ }^{21}$ The cardiac adverse effects 
have been linked to activation of adenosine receptors and may be related to serum levels. ${ }^{20}$ Because of the safety profile and superior bronchodilation effects of inhaled $\beta_{2}$ agonists, intravenous aminophylline is not recommended for the treatment of acute asthma. ${ }^{1}$ Aminophylline may have a role in refractory asthma, but patients with refractory asthma should be closely monitored for adverse effects.

\section{Magnesium Sulfate}

Magnesium sulfate interferes with calcium ion transport in the membranes of smooth-muscle cells, which results in relaxation. ${ }^{22,23}$ Various studies explored the effects of both nebulized and intravenous magnesium sulfate for the treatment of asthma exacerbations. A meta-analysis of 7 trials, with a total of 668 subjects with asthma, investigated the effects of intravenous magnesium sulfate in acute asthma and found no improvements in hospitalization rates or pulmonary function. ${ }^{24}$ However, a subgroup analysis of those subjects with severe asthma exacerbations (varying definitions at presentation: $\mathrm{FEV}_{1}<25-30 \%$ predicted, peak expiratory flow (PEF) $<60 \%$ predicted, or poor initial response to inhaled $\beta_{2}$ agonists), revealed improvements in hospitalization rates and lung function with a number needed to treat of 5.24

The studies of inhaled magnesium sulfate in asthma have mixed results. A study that compared the effects of nebulized magnesium sulfate as an add-on therapy to nebulized albuterol in 74 subjects with asthma and with mildto-moderate exacerbations showed no improvements in pulmonary function. ${ }^{25}$ In contrast, a placebo-controlled double-blind clinical trial that included 60 subjects undergoing a severe asthma exacerbation found improvements after treatment with inhaled magnesium sulfate in postbronchodilator $\mathrm{FEV}_{1}$ and oxygen saturation compared with placebo. ${ }^{26}$ Another study, in subjects with severe asthma exacerbations, defined as $\mathrm{FEV}_{1}<50 \%$ predicted on presentation, also showed improvements in lung function after adjuvant therapy with nebulized magnesium sulfate to salbutamol. ${ }^{27}$

Although it seems that, in the pediatric population, the use of nebulized magnesium may have a role in mild-tomoderate exacerbations, there is evidence that favors the use of this therapy in severe exacerbations. ${ }^{28}$ Most recently, Goodacre et $\mathrm{a}^{29}$ studied the effects of nebulized or intravenous magnesium sulfate in acute asthma in a large double-blind placebo-controlled multicenter trial. A total of 1,109 subjects with severe acute asthma evaluated in the emergency department from 34 centers in the United Kingdom were included in the study. ${ }^{29}$ The rate of hospitalization did not differ between the controls and either form of magnesium sulfate, and the rate of hospitalization also was not different between the nebulized or intravenous forms. ${ }^{29}$
Intravenous magnesium sulfate delivery was considered superior to the nebulized form with regard to breathlessness when measured by using a visual analog scale. ${ }^{29}$

Based on the current evidence, nebulized magnesium should not be routinely used in acute asthma. There is evidence that the use of intravenous magnesium sulfate is favored in selected cases. In patients with a severe asthma exacerbation with a poor initial response to inhaled $\beta_{2}$ agonists, an infusion of $2 \mathrm{~g}$ of magnesium sulfate delivered over 20 min may be considered. ${ }^{1}$

\section{Helium-Oxygen Therapy}

Helium-oxygen mixtures may increase the deposition of inhaled particles in the distal airways. Therefore, this mode of delivery of medications (ie, $\beta_{2}$ agonists) is an attractive alternative for the treatment of patients with asthma exacerbation. Various studies evaluated the efficacy of heliumoxygen mixtures in acute asthma. A systematic review, which included 10 studies and 697 subjects, showed that treatment with a helium-oxygen mixture was associated with a significant improvement in PEF. ${ }^{30}$ Notably, a subgroup analysis revealed that the effect was more prominent in subjects with severe and very-severe asthma. There also was a reduced rate of hospitalizations associated with the use of a helium-oxygen mixture. ${ }^{30}$ Current guidelines recommend the use of helium in patients who do not respond to standard therapies or in those patients with verysevere disease. ${ }^{1}$

\section{Epinephrine}

Epinephrine should be used only if asthma is associated with anaphylaxis or angioedema. It is recommended that this therapy should not be used routinely during an asthma exacerbation. ${ }^{1}$ Although epinephrine can be administered directly into an endotracheal tube, there is insufficient evidence to support the routine use of this mode of delivery in patients with respiratory failure due to acute asthma. ${ }^{31}$ If there is a history of anaphylaxis, the patient and close family should be proficient in the self-administration of epinephrine by using a pre-packaged self-injection kit. If an asthma exacerbation is associated with anaphylaxis, epinephrine should be administered as soon as the symptoms develop.

\section{Patient-Initiated Therapy}

All patients with asthma, particularly those with a history of exacerbations, should be provided with an asthma action plan. The asthma action plan is a set of written instructions created by the provider specifically for each patient. It provides a guide for patient-initiated therapy according to self-monitored symptoms and/or PEF, and 


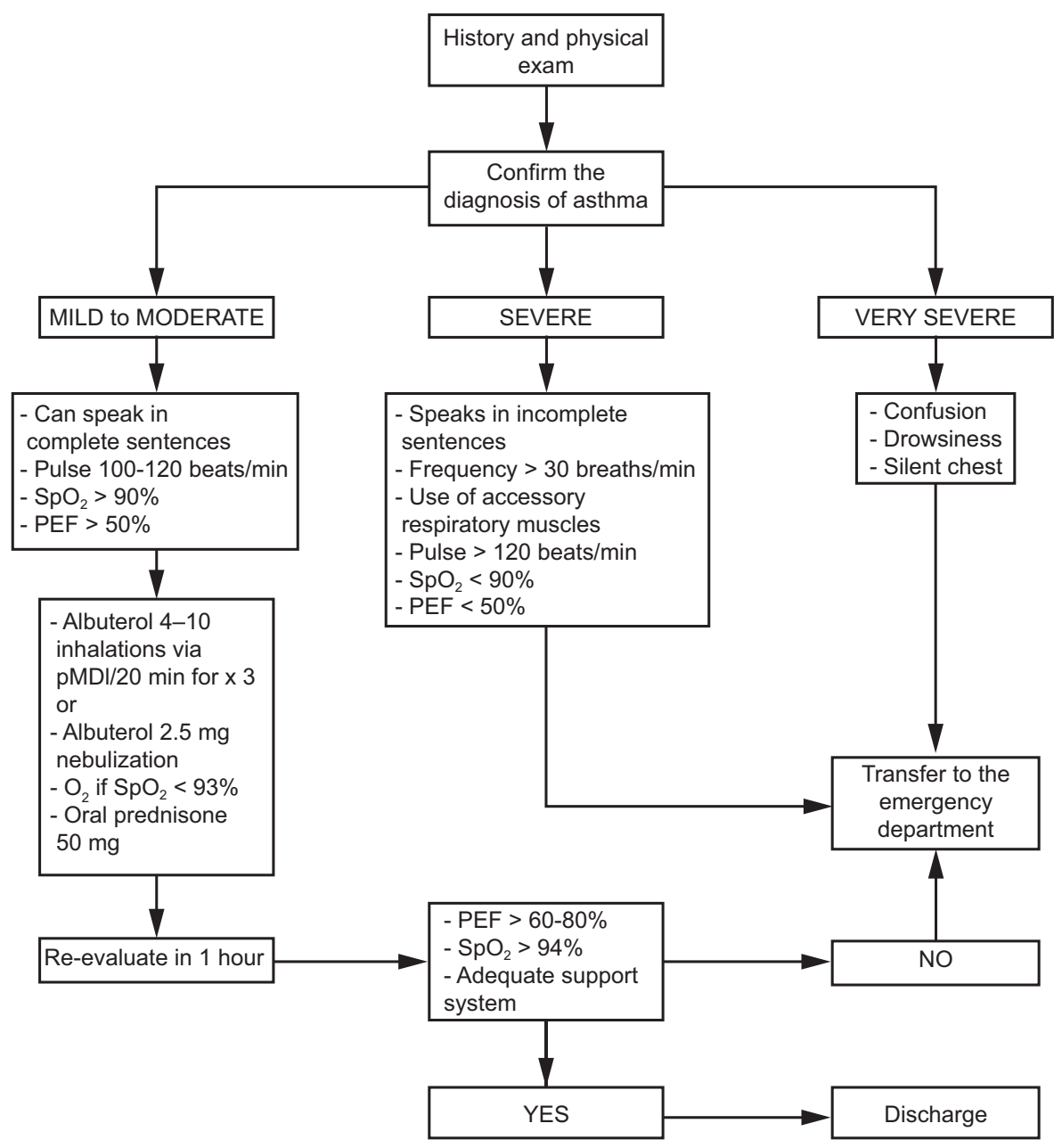

Fig. 1. Treatment of asthma in the out-patient setting. The diagnosis of asthma is based on a history, physical examination, family history, and spirometry. Disorders that mimic asthma include congestive heart failure, COPD, pulmonary embolism, vocal cord dysfunction, tracheal tumors, sarcoidosis, and foreign body aspiration. PEF = peak expiratory flow, pMDI = pressurized metered-dose inhaler. From Reference 1 , with permission.

provides a framework on when to seek medical care. ${ }^{1}$ The use of an asthma action plan has been associated with reductions in unscheduled office and emergency department visits and hospitalizations. ${ }^{32}$ An asthma action plan typically has recommendations regarding when to use extra doses of albuterol. The need for extra doses of albuterol after 1-2 d typically signals the need for additional therapy. Doubling the dose of inhaled corticosteroid may benefit some patients, but it has not been consistently shown to improve outcomes. ${ }^{18}$ In the majority of patients, the asthma action plan should include instructions regarding oral corticosteroids. It has been recommended for patients to receive $40-50 \mathrm{mg}$ of prednisone every day for 5-7 d if symptoms do not improve after 2-3 d of increasing the frequency of reliever inhaled medications (ie, albuterol), there is a rapid deterioration of their symptoms, the $\mathrm{FEV}_{1}$ or PEF to $<60 \%$ predicted, or if there is a history of severe and/or sudden exacerbations. ${ }^{1}$ At this point, patients should contact their provider to alert them about a self-managed exacerbation so that adjustments in the therapy can be made.

\section{Treatment in the Out-Patient Setting}

Unscheduled out-patient visits due to asthma are frequent. Patients evaluated in this setting for acute asthma should be interviewed and physical examined promptly to determine if there are any life-threatening conditions. A focused history and examination should be carried out in all patients. Even in those patients in whom asthma is a well-known diagnosis, an effort should be made to reasonably rule out asthma-mimicking conditions. The history should be focused on the timing of the symptoms, any identifiable cause (eg, exposures, infections, non-adherence), severity of symptoms, previous severe exacerbations, and any changes in medication regimens. ${ }^{1}$ The physical examination is critical to de- 
cide the level of care that the patient will require (Fig. 1). Patients with mild-to-moderate disease can speak in complete sentences, have an increased breathing frequency, a resting pulse of $100-120$ beats/min, oxygen saturation of $90-95 \%$, and PEF $>50 \%$ predicted.

Patients with a severe asthma exacerbation speak in incomplete sentences, typically sit in a forward position (also known as a tripod position), have a breathing frequency $>30$ breaths/min, use accessory respiratory muscles, have a resting pulse $>120$ beats/min, oxygen saturation $<90 \%$, and PEF $<50 \%$ predicted. Patients with life-threatening asthma present with confusion, drowsiness, and a silent chest on physical examination (the bronchospasm is so severe that there is minimal movement of air through the airways). Patients with a mild-to-moderate asthma exacerbation can be safely treated as an out-patient (Fig. 1).

These patients should be treated with albuterol 4-10 inhalations via pressurized metered-dose inhaler every $20 \mathrm{~min}$ for $1 \mathrm{~h}$ or a single nebulizer treatment $(2.5 \mathrm{mg}$ albuterol). Oral steroids should be administered at this time. Oxygen should be administered if oxygen saturation is $<93 \%$. After $1 \mathrm{~h}$, the patient should be reevaluated. If there is improvement in the symptoms or PEF, the patient may be discharged. The asthma action plan should be carefully reviewed with the patient, and oral corticosteroids should be continued for 5-7 d. A follow-up appointment should be scheduled 2-7 d later to verify the improvement of symptoms. ${ }^{1}$ Patients who do not improve after $1 \mathrm{~h}$ of therapy, or those with a severe or life-threatening exacerbation should be emergently transferred to the emergency department or acute care facility. While waiting for transport patients should be treated with albuterol and ipratropium bromide, oxygen, and systemic corticosteroids.

\section{Therapy in the Emergency Department}

Patients with mild-to-moderate asthma exacerbations may present to the emergency department to seek medical care. These patients should be treated as an out-patient when following the recommendation detailed above. Patients with severe or life-threatening asthma should always be managed in the emergency department. A focused, expedited history and physical examination should be carried out in all patients. It is critical to rule out other conditions that may mimic a severe asthma exacerbation, such as pneumonia, congestive heart failure, pneumothorax, and myocardial infarction. In patients with a severe exacerbation, careful attention should be placed on the level of consciousness, oxygen saturation, breathing frequency, resting pulse, and blood pressure, and on the use of accessory respiratory muscles. Patients with severe asthma may have a fast deterioration of their clinical presentation, so continuous monitoring of these patients is warranted. In the advanced stages of an asthma exacerbation, the pulmonary physical examination may reveal a silent chest, which may herald impending respiratory failure. Patients with severe asthma should also be monitored for potential complications of asthma, such as pneumothorax, pneumomediastinum, and anaphylaxis.

If possible, and without delaying therapy, all patients should have an objective measure of their lung function because health-care professionals may underestimate or overestimate the severity of the clinical presentation. PEF or $\mathrm{FEV}_{1}$ measurements should be performed every hour to assess the progression of the disease and determine the therapy and the need for hospitalization. An oxygen saturation of $<90 \%$ indicates the need for intense therapy. ${ }^{1}$ Arterial blood gas determinations are not indicated in all patients but should be considered in patients with $\mathrm{FEV}_{1}$ $<50 \%$ predicted. ${ }^{33}$ Patients with a $\mathrm{P}_{\mathrm{aO}_{2}}<60 \mathrm{~mm} \mathrm{Hg}$ or an oxygen saturation $<90 \%$ should be treated with supplemental oxygen. Although a chest radiograph is not routinely recommended in asthma, it should be obtained in all patients with atypical features and in those who do not respond to initial therapy.

Inhaled albuterol should be administered promptly. Although most patients will respond adequately to intermittent dosing, continuous nebulization has been effective in severe asthma exacerbations $(10-15 \mathrm{mg} / \mathrm{h}$ or $0.5 \mathrm{mg} / \mathrm{kg} / \mathrm{h}$ in children). ${ }^{7}$ Systemic corticosteroids should be administered within the first hour of presentation, unless the PEF or $\mathrm{FEV}_{1}$ is $>70 \%$ their personal best or of predicted after $30 \mathrm{~min}$ of therapy. All patients with moderate-to-severe exacerbations should receive systemic corticosteroids. $\mathrm{Pa}$ tients should be hospitalized if the PEF or $\mathrm{FEV}_{1}$ is $<25 \%$ of their personal best or of predicted before therapy, or if, after $1 \mathrm{~h}$ of therapy is $<40 \%$ of their personal best or predicted. ${ }^{34}$ Discharge may be considered, depending on the patient risk factors if the lung function is $40-60 \%$ predicted after therapy. Patients with a lung function $>60 \%$ should be discharged after consideration of the risk factors and with establishing appropriate follow-up. High-risk patients are those with a history of a near-death event or intubation, noncompliance, or psychiatric illness, or with difficulty accessing a medical care.

\section{Management of Patients Admitted to the Hospital: Wards and ICU Care}

Careful consideration must be given to the level of care required when a patient with an exacerbation of asthma is admitted to the hospital. In general, guidelines suggest that patients should be admitted for observation and further treatment if the pretreatment $\mathrm{FEV}_{1}$ or PEF is $<25 \%$ of predicted or of personal best or if the post-treatment values are $<40 \%$ after emergency department treatment. Typi- 
cally, patients who demonstrate a poor response to therapy $\left(<10 \%\right.$ increase in $\left.\mathrm{PEF} / \mathrm{FEV}_{1}\right)$, persistent or unresponsive hypercapnia, altered mental status, hypotension, or have significant comorbid conditions (myocardial ischemia, tachyarrhythmias, or pneumonia) should be admitted to the ICU.

Therapy on an in-patient unit is similar to treatment given in the emergency department and inhaled $\beta$ agonist $(2.5 \mathrm{mg}$ ) is usually given every $1-4 \mathrm{~h}$ by nebulization. Dosing intervals are usually based on the patient's clinical status by evaluating the level of dyspnea, breathing frequency, and $\mathrm{PEF} / \mathrm{FEV}_{1}$ before and after treatments. One study in hospitalized patients found that intermittent ondemand therapy resulted in fewer nebulizations, fewer palpitations, and a shorter hospital stay compared with 4-hourly intermittent therapy. ${ }^{35}$ Transitioning from nebulization to a pressurized metered-dose inhaler with a holding chamber can be initiated once the patient is stable, and, typically, 4-6 puffs of a short-acting $\beta$ agonist are given every 4-6 h. If the spacer and/or holding chamber is not made with anti-static plastic, then guidelines suggest that they be pre-washed with detergent and air-dried or primed with at least 20 puffs of albuterol before use. ${ }^{1}$

Although many patients maintain good oxygen saturations despite severe airway obstruction, some patients develop small airway mucus plugging even after the $\mathrm{PEF} / \mathrm{FEV}_{1}$ normalize. Guidelines suggest that oxygen should be administered via nasal cannula or oronasal mask to maintain an arterial oxygen saturation of 9395\% in adults and $94-98 \%$ in children. In severe exacerbations, low-flow oxygen therapy by titrating the saturation to $93-95 \%$ was associated with better physiological outcomes than with high-flow $100 \%$ oxygen therapy. $36-38$

The role of continuing short-acting anticholinergic therapy is controversial, and most guidelines do not recommend that ipratropium be continued once the patient is admitted to the hospital. One study in adults indicated that these patients benefitted from the addition of ipratropium for up to 3 days after admission. ${ }^{39}$ However, a study in hospitalized children found no benefit when nebulized ipratropium bromide was added to nebulized albuterol. ${ }^{13}$

The guidelines suggest that oral corticosteroids should be continued at a daily dose equivalent to $50 \mathrm{mg}$ of prednisolone or prednisone as a single morning dose or $200 \mathrm{mg}$ of hydrocortisone in divided doses for adults or 1-2 $\mathrm{mg} / \mathrm{kg} / \mathrm{d}$ up to a maximum dose of $40 \mathrm{mg}$ in children. ${ }^{1}$ This dose is continued for the duration of the hospitalization, and patients are frequently sent home after completing a 5-7-d course of prednisone for adults and 3-4-d course for children. Results of studies ${ }^{40,41}$ indicated that tapering the course of prednisone is not needed as long as the patient has been adherent to treatment with inhaled corticosteroids.

\section{Management of Status Asthmaticus in the ICU}

Patients admitted to the ICU include individuals who require ventilator support or those with severe asthma for whom therapy failed. Most often they have refractory hypercapnia, persisting or worsening hypoxemia, deteriorating $\mathrm{PEF} / \mathrm{FEV}_{1}$, drowsiness, confusion, or impending signs of respiratory arrest. Elective intubation by an experienced clinician is always recommended as soon as signs of deterioration are present. Intubation and mechanical ventilation may lead to hypotension and barotrauma secondary to high positive intrathoracic pressures. Care must be taken to assure that intravascular volume is adequate before intubation, and a bolus of intravenous normal saline solution is often recommended before initiation of mechanical ventilation.

An observational study by Darioli and Perret ${ }^{42}$ demonstrated a strategy of permissive hypercapnia, achieved by limiting peak airway pressures to $50 \mathrm{~cm} \mathrm{H}_{2} \mathrm{O}$, resulted in decreased mortality when compared with historic controls. Despite a lack of high-quality evidence that supports this practice, this approach has become the standard of care. Hypercapnic acidosis may cause cerebral vasodilatation, cerebral edema, and pulmonary vasoconstriction, and should be avoided in patients with increased intracranial pressure (as might occur with anoxic brain injury after cardiopulmonary arrest). However, hypercapnia is usually well tolerated by most patients as long as the $\mathrm{P}_{\mathrm{aCO}_{2}}$ does not exceed $90 \mathrm{~mm} \mathrm{Hg.}{ }^{42}$ Low values of arterial $\mathrm{pH}$ are tolerated by most patients, but sodium bicarbonate may be considered in the setting of an arterial $\mathrm{pH}<7.20 .{ }^{43}$

Although there are no studies that determined the optimal mode of mechanical ventilation, it seems prudent to use the mode with which one is most familiar. Most researchers have recommended an initial minute ventilation of $90-130 \mathrm{~mL} / \mathrm{kg}$ ideal body weight (approximately $6-9 \mathrm{~L} / \mathrm{min}$ for a $70-\mathrm{kg}$ patient), with further adjustments based on $\mathrm{pH}$ and the plateau airway pressure. Based on studies by Tuxen and Lane ${ }^{44}$ and Peters et al, ${ }^{45}$ we usually use a tidal volume of $8-9 \mathrm{~mL} / \mathrm{kg}$ with a breathing frequency of 10-14 breaths/min, a flow of $100 \mathrm{~L} / \mathrm{s}$, and 0 PEEP. However, many institutions prefer to use tidal volumes of $6-8 \mathrm{~mL} / \mathrm{kg}$ ideal body weight. ${ }^{44,45} \mathrm{We}$ adjust the setting to maintain a plateau pressure of $30 \mathrm{~cm} \mathrm{H}_{2} \mathrm{O}$ and judiciously adjust ventilator-applied PEEP based on its ability to lower intrinsic PEEP.

Special consideration for the treatment of severe asthma in the ICU needs to be addressed because larger and morefrequent doses are needed in acute severe asthma because the dose-response curve and the duration of activity are adversely affected by the degree of bronchoconstriction. ${ }^{46}$ Our approach for adults in the ICU is to use continuous nebulization of 
albuterol until the patient stabilizes, with a breathing frequency of $<30$ breaths/min, a heart rate $<120$ beats/min, and stable or improving hypercapnia. There are data to support the concept that higher doses of $\beta_{2}$ agonists are required in the setting of mechanical ventilation. MacIntyre et $\mathrm{al}^{47}$ demonstrated that only $2.9 \%$ of a radioactive aerosol delivered by a small-volume nebulizer was delivered to the lower airway. One approach is to measure the change in peak-toplateau pressure after nebulizing $2.5 \mathrm{mg}$ of albuterol and by observing the effect. If the peak-to-plateau pressure does not decrease by $\geq 15 \%$, then we increase the dose by $2.5 \mathrm{mg}$ in an incremental manner until the gradient decreases or the patient experiences toxicity (tachycardia or muscle tremors). With the newer high efficiency nebulizers, we have not had to go above a dose of $5.0 \mathrm{mg}$ for any patient.

Although guidelines suggest that patients with exacerbations of asthma should be treated with no more than $40-$ $80 \mathrm{mg}$ of prednisolone or $200 \mathrm{mg}$ of hydrocortisone per day, our practice has been to use higher doses of intravenous methylprednisolone in this population. Haskell et al ${ }^{48}$ showed that subjects with status asthmaticus who received $125 \mathrm{mg}$ of intravenous methylprednisolone every $6 \mathrm{~h}$ improved more rapidly than subjects who received $40 \mathrm{mg}$ of drug over the first $2 \mathrm{~d}$ of treatment. Both 125-mg and 40-mg doses were superior to the $15 \mathrm{mg}$ every 6-h dose. ${ }^{48}$ Although the ultimate improvement was not different in this study, we tend to use the higher doses of corticosteroids for the first 24-48 h unless the patient has poorly controlled diabetes. This study was not powered to show a difference in length of intubation or ICU stay but supports the concept of considering higher doses of corticosteroids in patients with severe asthma who are intubated. ${ }^{48}$ Adverse effects, such as hyperglycemia, sleep disturbance, or mental status changes, may be more likely at these higher doses.

\section{Unproved Alternate Therapy in Status Asthmaticus}

Although the application of noninvasive ventilation (NIV) has proved to be safe and effective in COPD, the use of NIV in severe asthma is not clearly defined. A systematic review found 5 studies with $>200$ subjects with severe asthma randomized to NIV or placebo. ${ }^{49}$ Two of the studies found no difference in the number of subjects who required intubation and mechanical ventilation; ${ }^{50,51}$ whereas one study demonstrated fewer admissions in the NIV group. ${ }^{50}$ NIV should not be attempted in patients who are agitated or uncooperative, and patients should be monitored closely if NIV is attempted. Although retrospective studies are encouraging about the potential benefits of NIV, in our experience, many patients with acute, severe asthma are unable to tolerate NIV. ${ }^{52,53}$

Although intravenous aminophylline is not likely to result in any additional bronchodilation when compared with stan- dard care with inhaled bronchodilators and corticosteroids, some patients with near-fatal asthma may gain benefit with intravenous aminophylline. ${ }^{8}$ The usual loading dose of $5 \mathrm{mg} / \mathrm{kg}$ is given intravenously over $20 \mathrm{~min}$ and then infused at a rate of $0.5-0.7 \mathrm{mg} / \mathrm{kg} / \mathrm{h}$. Such patients are rare, and the potential adverse effects are not uncommon (arrhythmias and vomiting). Blood levels should be checked daily for all patients receiving aminophylline infusions.

Oral leukotriene inhibitors have been shown to increase $\mathrm{FEV}_{1}$ within 1-2 $\mathrm{h}$, but their usefulness in the setting of exacerbation of asthma is unclear. In a randomized placebo-controlled trial of $>500$ adults with severe asthma $\left(\mathrm{FEV}_{1} \leq 50 \%\right.$ after $1 \mathrm{~h}$ of treatment), intravenous montelukast significantly improved the $\mathrm{FEV}_{1}$ at $60 \mathrm{~min}$ but did not reduce the need for hospitalization. ${ }^{54}$ Because oral montelukast is rapidly absorbed and has a strong safety profile, we have used $10 \mathrm{mg}$ of montelukast via the oralgastric tube in intubated patients with asthma for whom initial therapy failed.

The routine use of systemic $\beta_{2}$ agonists are not recommended in the routine therapy of exacerbations of asthma. Some guidelines suggest the potential benefit of subcutaneous epinephrine in patients who do not respond to standard therapy or if there is a suspicion of anaphylaxis. ${ }^{1}$ In one study, $60 \%$ of the subjects who did not respond to $2 \mathrm{~h}$ of inhaled $\beta_{2}$ agonists, expiratory flow increased after subcutaneous administration of epinephrine. ${ }^{55}$ It should not be used in patients with coronary artery disease, and care must be taken to avoid hypokalemia, lactic acidosis, or tachyarrhythmias.

Historically, general anesthesia was occasionally used in patients with refractory status asthmaticus. More recently, propofol and ketamine have been used because of their ability to reduce bronchoconstriction. Propofol can be titrated to anesthetic depth sedation and often reduces the need of neuromuscular blockade in patients with a rapid breathing frequency, but caution should be exercised because there have been reports of propofol-induced bronchospasm. ${ }^{56}$ Ketamine, an intravenous general anesthetic, has sedative, analgesic, and bronchodilating properties. ${ }^{57}$ Ketamine has sympathomimetic properties and may increase intracranial and systemic blood pressure, and may induce tachycardia.

There are case reports of the use of extracorporeal life support in patients with refractory status asthmaticus who have progressive hypercapnia and respiratory acidosis despite mechanical ventilation and aggressive inhaled and systemic therapy. ${ }^{58}$ Fulminant asthma would seem like an ideal setting for extracorporeal life support because the disorder is reversible and seldom associated with multi-organ failure. Fortunately, extracorporeal life support is rarely indicated because the outcome with more conservative therapy is almost always successful. However, results of studies indicate that it may be 
beneficial in rare cases of refractory hypoxemia or unresponsive and progressive respiratory acidosis..$^{59,60}$

\section{Postdischarge Therapy and Importance of an Action Plan}

Before discharge from the hospital or the emergency department, arrangements for follow-up within 1-2 weeks should be made for patients. Patients who are hospitalized for their asthma may be especially receptive to information and advice about how to control symptoms and avoid future exacerbations. Health-care providers or an asthma educator should provide detailed education to all patients before discharge. Discussion should assure that the patient understands the cause of his or her exacerbation, modifiable risks factors (including avoidance of triggers and environmental tobacco smoke), the purpose and correct use of medications, and an updated asthma action plan. The action plan should identify each discharge medication, the dose, and frequency. It should also outline how often to take the quick reliever medications if symptoms increase or $\mathrm{PEF} / \mathrm{FEV} \mathrm{V}_{1}$ decreases, when to consider taking oral corticosteroids, and how to reach their primary care provider or obtain emergency care if their asthma does not respond to a step-up in therapy. Patients $>5 \mathrm{y}$ of age usually are discharged with a flow meter, with instructions to keep track of their values until they are seen in follow-up. This is especially important for patients with brittle asthma (significant variability in their PEF) or for patients identified at risk for near-fatal exacerbations of asthma. Patients should demonstrate the proper use of their inhalers and be discharged with a sufficient quantity of medication to last for at least $1-2$ months.

\section{Summary}

Asthma exacerbations are important events in the course of asthma. A history and physical examination are important to determine the severity of an asthma exacerbation and help distinguish these episodes from other pulmonary conditions that may present with acute respiratory deterioration. Shortacting bronchodilators should be started as soon as the diagnosis of an asthma exacerbation is confirmed. Systemic corticosteroids should be administered without delay, and, unless there is a contraindication, the oral route is preferred. Nebulized magnesium is not routinely recommended based on the findings of recent trials. Although controversy exists, intravenous magnesium sulfate can be beneficial in severe exacerbations. Methylxanthines are not routinely used during an asthma exacerbation but have been useful in selected cases of status asthmaticus. Epinephrine is not recommended during an asthma exacerbation, unless there is associated anaphylaxis. Helium-oxygen mixtures may be used in patients who do not respond to standard therapies or those with severe disease.

\section{REFERENCES}

1. Global Initiative for Asthma (GINA). GINA Report, Global Strategy for Asthma Management and Prevention, 2017. http://www.ginasthma. org. Accessed on June 1, 2017.

2. Bateman ED, Boushey HA, Bousquet J, Busse WW, Clark TJ, Pauwels RA, Pedersen SE. Can guideline-defined asthma control be achieved? The Gaining Optimal Asthma ControL study. Am J Respir Crit Care Med 2004;170(8):836-844.

3. Wamboldt MZ, Bihun JT, Szefler S, Hewitt J. Perception of induced bronchoconstriction in a community sample of adolescents. J Allergy Clin Immunol 2000;106(6):1102-1107.

4. Magadle R, Berar-Yanay N, Weiner P. The risk of hospitalization and near-fatal and fatal asthma in relation to the perception of dyspnea. Chest 2002;121(2):329-333.

5. Newman KB, Milne S, Hamilton C, Hall K. A comparison of albuterol administered by metered-dose inhaler and spacer with albuterol by nebulizer in adults presenting to an urban emergency department with acute asthma. Chest 2002;121(4):1036-1041.

6. Rodrigo GJ, Rodrigo C. Continuous vs intermittent beta-agonists in the treatment of acute adult asthma: a systematic review with metaanalysis. Chest 2002;122(1):160-165.

7. Camargo CA Jr, Spooner CH, Rowe BH. Continuous versus intermittent beta-agonists in the treatment of acute asthma. Cochrane Database Syst Rev 2003;(4):CD001115

8. Travers AH, Jones AP, Camargo CA Jr, Milan SJ, Rowe BH. Intravenous beta(2)-agonists versus intravenous aminophylline for acute asthma. Cochrane Database Syst Rev 2012;12:CD010256.

9. Travers AH, Milan SJ, Jones AP, Camargo CA Jr, Rowe BH. Addition of intravenous beta(2)-agonists to inhaled beta(2)-agonists for acute asthma. Cochrane Database Syst Rev 2012;12:CD010179.

10. Louridas G, Kakoura M, Galanis N, Patakas D, Kastritsi K. Bronchodilatory effect of inhaled versus oral salbutamol in bronchial asthma. Respiration 1983;44(6):439-443.

11. Rodrigo GJ, Castro-Rodriguez JA. Anticholinergics in the treatment of children and adults with acute asthma: a systematic review with meta-analysis. Thorax 2005;60(9):740-746.

12. Kirkland SW, Vandenberghe C, Voaklander B, Nikel T, Campbell S, Rowe BH. Combined inhaled beta-agonist and anticholinergic agents for emergency management in adults with asthma. Cochrane Database Syst Rev 2017;1:CD001284.

13. Griffiths B, Ducharme FM. Combined inhaled anticholinergics and shortacting beta2-agonists for initial treatment of acute asthma in children. Cochrane Database Syst Rev 2013;(8):CD000060.

14. Lahn M, Bijur P, Gallagher EJ. Randomized clinical trial of intramuscular vs oral methylprednisolone in the treatment of asthma exacerbations following discharge from an emergency department. Chest 2004;126(2):362-368.

15. Hasegawa T, Ishihara K, Takakura S, Fujii H, Nishimura T, Okazaki M, et al. Duration of systemic corticosteroids in the treatment of asthma exacerbation; a randomized study. Intern Med 2000;39(10):794-797.

16. Jones AM, Munavvar M, Vail A, Aldridge RE, Hopkinson L, Rayner C, O'Driscoll BR. Prospective, placebo-controlled trial of 5 vs 10 days of oral prednisolone in acute adult asthma. Respir Med 2002; 96(11):950-954.

17. Rowe BH, Spooner CH, Ducharme FM, Bretzlaff JA, Bota GW. Corticosteroids for preventing relapse following acute exacerbations of asthma. Cochrane Database Syst Rev 2007;(3):CD000195.

18. Kew KM, Quinn M, Quon BS, Ducharme FM. Increased versus stable doses of inhaled corticosteroids for exacerbations of chronic asthma in adults and children. Cochrane Database Syst Rev 2016; (6):CD007524.

19. Edmonds ML, Milan SJ, Camargo CA Jr, Pollack CV, Rowe BH. Early use of inhaled corticosteroids in the emergency department 
treatment of acute asthma. Cochrane Database Syst Rev 2012;12: CD002308.

20. Barnes PJ. Theophylline. Pharmaceuticals (Basel) 2010;3(3):725-747.

21. Nair P, Milan SJ, Rowe BH. Addition of intravenous aminophylline to inhaled beta(2)-agonists in adults with acute asthma. Cochrane Database Syst Rev 2012;12:CD002742.

22. Kumasaka D, Lindeman KS, Clancy J, Lande B, Croxton TL, Hirshman CA. MgSO4 relaxes porcine airway smooth muscle by reducing Ca2+ entry. Am J Physiol 1996;270(3 Pt 1):L469-L474.

23. Gourgoulianis KI, Chatziparasidis G, Chatziefthimiou A, Molyvdas PA. Magnesium as a relaxing factor of airway smooth muscles. J Aerosol Med 2001;14(3):301-307.

24. Rowe BH, Bretzlaff JA, Bourdon C, Bota GW, Camargo CA Jr. Intravenous magnesium sulfate treatment for acute asthma in the emergency department: a systematic review of the literature. Ann Emerg Med 2000;36(3):181-190.

25. Bessmertny O, DiGregorio RV, Cohen H, Becker E, Looney D, Golden $\mathrm{J}$, et al. A randomized clinical trial of nebulized magnesium sulfate in addition to albuterol in the treatment of acute mild-to-moderate asthma exacerbations in adults. Ann Emerg Med 2002;39(6):585-591.

26. Gallegos-Solórzano MC, Pérez-Padilla R, Hernández-Zenteno RJ. Usefulness of inhaled magnesium sulfate in the coadjuvant management of severe asthma crisis in an emergency department. Pulm Pharmacol Ther 2010;23(5):432-437.

27. Hughes R, Goldkorn A, Masoli M, Weatherall M, Burgess C, Beasley R. Use of isotonic nebulised magnesium sulphate as an adjuvant to salbutamol in treatment of severe asthma in adults: randomised placebo-controlled trial. Lancet 2003;361(9375):2114-2117.

28. Mahajan P, Haritos D, Rosenberg N, Thomas R. Comparison of nebulized magnesium sulfate plus albuterol to nebulized albuterol plus saline in children with acute exacerbations of mild to moderate asthma. J Emerg Med 2004;27(1):21-25.

29. Goodacre S, Cohen J, Bradburn M, Gray A, Benger J, Coats T. Intravenous or nebulised magnesium sulphate versus standard therapy for severe acute asthma (3Mg trial): a double-blind, randomised controlled trial. Lancet Respir Med 2013;1(4):293-300.

30. Rodrigo GJ, Castro-Rodriguez JA. Heliox-driven $\beta 2$-agonists nebulization for children and adults with acute asthma: a systematic review with meta-analysis. Ann Allergy Asthma Immunol 2014;112(1):29-34.

31. Nutbeam T, Fergusson A. Towards evidence based emergency medicine: Best BETs from the Manchester Royal Infirmary. BET 2: Is endotracheal adrenaline useful in acute asthma? Emerg Med J 2009; 26(6):435

32. Gibson PG, Powell H, Coughlan J, Wilson AJ, Abramson M, Haywood $\mathrm{P}$, et al. Self-management education and regular practitioner review for adults with asthma. Cochrane Database Syst Rev 2003; (1):CD001117.

33. Carruthers DM, Harrison BD. Arterial blood gas analysis or oxygen saturation in the assessment of acute asthma? Thorax 1995;50(2):186188.

34. Grunfeld A, FitzGerald J. Discharge considerations for adult asthmatics patients treated in emergency departments. Car Respir J 1996; 3:322-327.

35. Bradding P, Rushby I, Scullion J, Morgan MD. As-required versus regular nebulized salbutamol for the treatment of acute severe asthma. Eur Respir J 1999;13(2):290-294.

36. Chien JW, Ciufo R, Novak R, Skowronski M, Nelson J, Coreno A, McFadden ER Jr. Uncontrolled oxygen administration and respiratory failure in acute asthma. Chest 2000;117(3):728-733.

37. Rodrigo GJ, Rodriquez Verde M, Peregalli V, Rodrigo C. Effects of short-term $28 \%$ and $100 \%$ oxygen on $\mathrm{PaCO} 2$ and peak expiratory flow rate in acute asthma: a randomized trial. Chest 2003;124(4):1312-1317.

38. Perrin K, Wijesinghe M, Healy B, Wadsworth K, Bowditch R, Bibby $\mathrm{S}$, et al. Randomised controlled trial of high concentration versus titrated oxygen therapy in severe exacerbations of asthma. Thorax 2011;66(11):937-941.

39. Brophy C, Ahmed B, Bayston S, Arnold A, McGivern D, Greenstone M. How long should Atrovent be given in acute asthma? Thorax 1998;53(5):363-367.

40. Lederle FA, Pluhar RE, Joseph AM, Niewoehner DE. Tapering of corticosteroid therapy following exacerbation of asthma. A randomized, double-blind, placebo-controlled trial. Arch Intern Med. 1987; 147(12):2201-2203.

41. O'Driscoll BR, Kalra S, Wilson M, Pickering CA, Carroll KB, Woodcock AA. Double-blind trial of steroid tapering in acute asthma. Lancet. 1993;341(8841):324-327.

42. Darioli R, Perret C. Mechanical controlled hypoventilation in status asthmaticus. Am Rev Respir Dis 1984;129(3):385-387.

43. Menitove SM, Goldring RM. Combined ventilator and bicarbonate strategy in the management of status asthmaticus. Am J Med 1983; 74(5):898-901.

44. Tuxen DV, Lane S. The effects of ventilatory pattern on hyperinflation, airway pressures, and circulation in mechanical ventilation of patients with severe air-flow obstruction. Am Rev Respir Dis 1987; 136(4):872-879.

45. Peters JI, Stupka JE, Singh H, Rossrucker J, Angel LF, Melo J, Levine SM. Status asthmaticus in the medical intensive care unit: A 30-year experience. Respir Med 2012;106(3):344-348.

46. Kelly HW. New beta 2-agonist aerosols. Clin Pharm Ther 1985;4(4): 393-403.

47. MacIntyre NR, Silver RM, Miller CW, Schuler F, Coleman RE. Aerosol delivery in intubated, mechanically ventilated patients. Crit Care Med 1985;13(2):81-84

48. Haskell RJ, Wong BM, Hansen JE. A double-blind, randomized clinical trial of methylprednisolone in status asthmaticus. Arch Intern Med 1983;143(7):1324-1327.

49. Lim WJ, Mohammed Akram R, Carson KV, Mysore S, Labiszewski NA, Wedzicha JA, et al. Non-invasive positive pressure ventilation for treatment of respiratory failure due to severe acute exacerbations of asthma. Cochrane Database Syst Rev 2012;12:CD004360.

50. Soroksky A, Stav D, Shpirer I. A pilot prospective, randomized, placebo-controlled trial of bilevel positive airway pressure in acute asthmatic attack. Chest 2003;123(4):1018-1025.

51. Gupta D, Nath A, Agarwal R, Behera D. A prospective randomized controlled trial on the efficacy of noninvasive ventilation in severe acute asthma. Respir Care 2010;55(5):536-543.

52. Murase K, Tomii K, Chin K, Tsuboi T, Sakurai A, Tachikawa R, Harada Y, Takeshima Y, Hayashi M, Ishihara K. The use of noninvasive ventilation for life-threatening asthma attacks: Changes in the need for intubation. Respirology. 2010;15(4):714-720.

53. Alves D, Freitas AS, Jacinto T, Vaz MS, Lopes FO, Fonseca JA. Increasing use of non-invasive ventilation in asthma: a long-term analysis of the Portuguese national hospitalization database. J Asthma. 2014;51(10):1068-1075.

54. Camargo CA Jr, Gurner DM, Smithline HA, Chapela R, Fabbri LM, Green SA, et al. A randomized placebo-controlled study of intravenous montelukast for the treatment of acute asthma. J Allergy Clin Immunol 2010;125(2):374-380.

55. Appel D, Karpel JP, Sherman M. Epinephrine improves expiratory flow rates in patients with asthma who do not respond to inhaled metaproterenol sulfate. J Allergy Clin Immunol 1989; 84(1):90-98.

56. Takahashi S, Uemura A, Nakayama S, Miyabe M, Toyooka H. Bronchospasms and wheezing after induction of anesthesia with propofol in patients with a history of asthma. J Anesth 2002; 16(4):360-361. 
57. Stemp LI. Ketamine for status asthmaticus with respiratory failure. J Emerg Med 2014;47(5):571-572.

58. Mikkelsen ME, Pugh ME, Hansen-Flaschen JH, Woo YJ, Sager JS. Emergency extracorporeal life support for asphyxic status asthmaticus. Respir Care 2007;52(11):1525-1529.

59. Di Lascio G, Prifti E, Messai E, Peris A, Harmelin G, Xhaxho R, Fico A, Sani G, Bonacchi M. Extracorporeal membrane oxygenation support for life-threatening acute severe status asthmaticus. Perfusion. 2017;32(2):157-163.

60. Yeo HJ, Kim D, Jeon D, Kim YS, Rycus P, Cho WH. Extracorporeal membrane oxygenation for life-threatening asthma refractory to mechanical ventilation: analysis of the Extracorporeal Life Support Organization registry. Crit Care 2017;21(1):297.

\section{Discussion}

Peters: I'll start off by asking a question of myself and of the others here. In the asthma literature, when someone comes in with acute severe asthma you start by checking a peak flow or $\mathrm{FEV}_{1}$. The patient is often breathing 30 breaths/min and very tachycardic. You start the treatment, and, after $30 \mathrm{~min}$ to an hour of treatment, the patient's breathing frequency and heart rate are better, yet the patient's peak flow and $\mathrm{FEV}_{1}$ have not significantly improved. How do you explain this? My answer to this is, obviously, when you have significant air trapping, you dilate your airways, and, as you get rid of the trapped air, your $\mathrm{FEV}_{1}$ and peak flow may not change but your residual volume decreases and your work of breathing improves. So, the physiology of acute asthma has some features similar to COPD studies that show that one cannot rely solely on the change in $\mathrm{FEV}_{1}$ to determine if a bronchodilator therapy is beneficial. ${ }^{1}$ I say that, without doing lung volumes or some assessment of air-trapping, you really don't know what the optimal treatment is.

Rubin: Jay, your last comment I think nailed it. When we hear world experts talk about acute asthma, they talk about inflammation and bronchospasm and mucus hypersecretion, and then they'll speak for 45 min about biomarkers, bronchospasm, and medications, and I never hear mucus again. And, indeed, there are some patients who have what we call secretory hyper-responsiveness, ${ }^{2}$ which seems to be driven, in part, by neutrophil elastase. Some of these patients have cough dominant asthma; we used to call it cough variant asthma but cough dominant is preferred because nearly all have additional asthma symptoms when queried. These are the patients who, when we do a bronchial challenge test, have a slow recovery in their lung function. These are also some of the patients who we're looking at, but there seems to be a subgroup of these secretory hyperresponders. We've postulated that they may be a subgroup of patients who respond better to anticholinergics.

Peters: That's very interesting. As a junior faculty, we would see these people admitted to the hospital, and their FEV ${ }_{1}$ would completely normalize, and they would say, "I feel fine" but they were still hypoxic and requiring $\mathrm{O}_{2}$. We would say: "OK, let's work them up for pulmonary embolism and get a CT angiogram. They would often get this huge workup and then, over 4-5 days, they would finally normalize the oxygen saturation on room air. Sometimes we would start them on CPAP or BPAP. Frequently, these asthmatics would come in over and over again with the same problem, and, after the second or third admission, we would finally say, "OK this is either small airway mucus plugging with hypoxia or its micro-atelectasis. So let's quit working them up for shunts and other causes of hypoxemia because they clearly follow the same pattern over and over." I think as we see these patients, we get more comfortable saying exactly what you said is their pathophysiology. Some asthmatics clearly develop mucus plugging and atelectasis that requires a longer period of time to resolve than their bronchospasm.
Rubin: People in the ICU who die of asthma don't die of albuterol deficiency, and they've almost all received steroids; if they haven't, it's surprising. Studies that looked at fatal asthma, particularly the large Prairie Provinces fatal asthma study some 20 years ago, showed that, on autopsy, these airways are just plugged up with mucus, ${ }^{3,4}$ and the mucus in asthma is actually far more viscous and tenacious than that of either cystic fibrosis or COPD secretions.

Peters: Again, this wasn't a talk about mechanical ventilation or I might have to take my gloves out and challenge Neil [MacIntyre] to a boxing match because we approach mechanical ventilation in status asthmaticus quite differently. ${ }^{5}$ However, I think the smartest thing Neil ever said to me was "Use the mode of ventilation you're most comfortable with" because these patients have complicated and dynamic airway physiology and you really need to know how to make adjustments in your ventilator settings. So we don't use pressure control in our medical ICU because that is not the mode we use the most. But I feel Bruce [Rubin] is right, mucus plugging is a big problem and may require changes in ventilator settings and close observation in suctioning these patients when secretions cause problems.

MacIntyre: I don't think we disagree much at all. I think the way you harm someone on a ventilator with asthma (or COPD, for that matter) is you don't recognize the air-trapping and how much it's driving up overinflation of the thorax and how much it's impairing venous return. I think the air-trapping, like Bruce said, is 
driven to a large extent by small airways and mucus plugging.

Peters: We went through and looked at all the early literature. ${ }^{6-8}$ Almost every death in people with status asthmaticus $(>80 \%)$ was related to anoxic brain injury from acute cardiopulmonary arrest on the wards before they got to the ICU. There are patients who are morning dippers who develop worsening obstruction late at night. ${ }^{9}$ I feel that our failure to follow peak flows or $\mathrm{FEV}_{1}$ for the first couple of days is very big mistake because some patients do pretty well where their peak flows are up at $60-70 \%$ and the next morning they're down to $30-40 \%$. Those people really need to be in a monitored area and are at high risk for ending up in the ICU.

*Newhouse: The corollary of what has just been said by Bruce and Neil is that the $\mathrm{FEV}_{1}$ and peak flow are lousy tests of peripheral airway obstruction.

Peters: Well said.

$\dagger$ Hess: Your hypothesis of why NIV may be beneficial in asthma due to reversing atelectasis is appealing. But could it also be the result of the positive pressure providing mechanical bronchodilation, as a non-medication bronchodilator?

Peters: It's interesting because, in the physiology literature, the strongest bronchodilator I know is a healthy patient taking a large, deep breath. If you think about it, that theory that positive pressure may be acting as a bronchodilator rather than just getting rid of the atelectasis is also quite interesting.

MacIntyre: Just be careful; it's a two-edged sword. The positive pressure may offer some advantages as you guys have described, but it can also contribute to the air-trapping.

Peters: That's a very good point. In the studies by Tuxen ${ }^{10}$ and others, you see that the inappropriate use of PEEP may do more harm than good. We try to only use PEEP in low doses when using ventilation in patients in status asthmaticus and only when we can document that the static compliance gets better and the air-trapping actually gets less when we add PEEP. I feel PEEP is a double-edged sword in this setting.

$\dagger$ Hess: But is not that a minute ventilation effect primarily?

MacIntyre: Oh yes. The 3 factors that drive air-trapping are minute ventilation, the inspiratory-expiratory ratio, and lung mechanics.

Lugogo: I agree with what was said regarding the most common cause of death in fatal asthma events. In my experience, the patients who died of status asthmaticus died of complications related to acute brain injury. In the few cases I have seen, the patients had cardiopulmonary arrest at home, which seems to me is an indication that people don't know when they're in trouble or underperceive the fact that they are in trouble. Quite often it seems like these patients are those with milder asthma at baseline and, therefore, are not on any therapy before the fatal event. In fact, our patients with severe asthma seem to be the ones who know what to do. They tend to double their steroids and use their bronchodilators, and call the office for assistance with their symptoms. It is the people who are not quite as severe who don't have the perception of when things are going south. I know that there is a small proportion of patients who have acute asphyxic asthma who go from being well to not well very quickly, and that's a tricky situation. But the vast majority of people have days of slowly progressive deterioration in symptoms before they become acutely unstable. Unfortunately, by the time they call for help, depending on where they live, they might have suffered a cardiopul- monary arrest. In spite of this, most patients are successfully resuscitated and are able to be treated for the acute asthma episode. They get through the status asthmaticus but die of the brain injury.

Peters: That's a very good point because most people who die of asthma die before they ever get to the hospital. I was talking about the percentage who die in the hospital, and usually they die of either complicating factors (eg, pneumonia or sepsis) or their severe disease. They also die because physicians underestimate their severity and they're admitted to the ward rather than in an area where they're closely observed. But that's a very good point. Every year we have a case in our city of a young person who died at home, many of them with mild asthma who unexpectedly had an acute severe attack. It also brings up the point that patients with severe asphyxic asthma have severe exacerbations associated with the use of aspirin or nonsteroidal anti-inflammatory drugs. Again, the EPR-3 guidelines ${ }^{11}$ recommend that patients with asthma severe enough to be hospitalized avoid aspirin and nonsteroidal anti-inflammatory drugs.

*Newhouse: There's the very famous silent chest story, where the patient is sent to the floor because the wheezing has gone away and was found dead the next morning.

Wise: I would like to raise a question. You mentioned treatment of gastroesophageal reflux disease in asthma and we've done studies in both adults and children without symptomatic gastroesophageal reflux disease or heartburn, and the use of proton pump inhibitors in those kids was not at all effective in preventing asthma exacerbations. ${ }^{12,13}$

Peters: I think that's very important to stress. There are randomized controlled studies that randomized 
subjects with asthma to proton pump inhibitors or placebo, showing no benefit in patients who did not have symptomatic gastroesophageal reflux disease. However, there is a study published by the National Jewish group ${ }^{14}$ that evaluated subjects with refractory asthma who did not respond to maximum asthma therapy. When they performed an endoscopy, they found pretty significant upper airway and esophageal changes consistent with gastroesophageal reflux disease. These subjects' asthma improved with aggressive gastroesophageal reflux disease therapy, and some even required surgical fundoplication to control their asthma. ${ }^{14}$ However, we are talking about a very small subgroup of asthmatics. I sure don't want to give the impression that any information suggests that everybody with significant asthma should be put on gastroesophageal reflux disease therapy.

George: The EPR-311 doesn't do a good job of talking about managing acute asthma in community settings. Evidence of that is in New York City and Philadelphia; we usually have one kid die in school every year. Now, the EPR-3 did release a separate 2-page report ${ }^{15}$ for school nurses on how to manage asthma in the schools, it's not integrated into the regular guidelines, and I don't see that in the Global Initiative for Asthma ${ }^{16}$ either. You're talking about an area where you have a lot of children with asthma, nurses who may or may not be in the schools for any routine period, and kids are being managed by a variety of different individuals, their albuterol is being held away from them (eg, in the school office) and when they understand that the kid is having an asthma flare they usually go to 2 puffs every 4 hours. I think this is a gap in the guidelines that really needs to be addressed if we're going to have some impact.

Giordano: I want to go back to the question I posed to Bob [Wise] pre- viously, with regard to regularly scheduling short-acting $\beta_{2}$ agonists. The reason I keep beating this drum is that we have precious little time with patients with chronic lung diseases when they're in acute care settings, and we need to leverage that time to the maximum to prepare them for success after discharge. This must include clawing back time we spend with these patients on unnecessary care. We could be sending respiratory therapists or others into these rooms to better prepare and educate our patients and families. When assuming that short-acting $\beta_{2}$ agonists are not used as a treatment enhancer vis à vis what Bruce described but just a straight 4 times a day (or other frequency) after they've resolved their difficulties. So it's about reviewing the order after the patient's initial order. Many initial orders do not get reviewed or modified based on patient improvement for the length of their hospital stay.

Peters: I'm glad you brought that up again because the guidelines reference a study that randomized subjects after the first $2 \mathrm{~h}$ of treatment to either 4 times a day albuterol versus treatment when requested by the subject. ${ }^{17}$ This study showed equivalent or even better outcomes with a shorter length of stay in the as-needed group. I couldn't agree with you more, if the time saved could be used by the respiratory therapist in providing asthma education, I think we would be far better off. Finally, I'd like to stress that we teach school nurses and physicians in an annual asthma education course. The hardest thing to teach them is how to write an asthma action plan. It's hard for me to believe that there are practicing physicians who have never written an asthma action plan. We have a long way to go in terms of getting well-written, logical action plans into the hands of patients.

\section{REFERENCES}

1. McFadden ER Jr, Kiser R, DeGroot WJ Acute bronchial asthma. Relations between clinical and physiologic manifestations. N Engl J Med 1973;288(5):221225.

2. Rubin BK, Priftis KN, Schmidt HJ, Henke MO. Secretory hyperresponsiveness and pulmonary mucus hypersecretion. Chest 2014;146(2):496-507.

3. Hessel PA, Mitchell I, Tough S, Green FH, Cockcroft D, Kepron W, Butt JC; Prairie Provinces Asthma Study Group. Risk factors for death from asthma. Prairie Provinces Asthma Study Group. Ann Allergy Asthma Immunol 1999;83(5): 362-368

4. Rubin BK, Tomkiewicz R, Fahy JV, Green FH. Histopathology of fatal asthma: drowning in mucus. Pediatr Pulmonol 2001; (Suppl 23):88-89.

5. Mansel JK, Stogner SW, Petrini MF, Norman JR. Mechanical ventilation in patients with acute severe asthma. Am J Med 1990; 89(1):42-48.

6. Webb AK, Bilton AH, Hanson GC. Severe bronchial asthma requiring ventilation. A review of 20 cases and advice and management. Postgrad Med J 1979;55(641):161170.

7. Picado C, Montserrat JM, Roca J, Rodríguez-Roisin R, Estopá R, Xaubet A, et al. Mechanical ventilation in severe exacerbation of asthma. Study of 26 cases with six deaths. Eur J Respir Dis 1983;64(2):102107.

8. Hetzel MR, Clark TJ, Branthwaite MA. Asthma: analysis of sudden deaths and ventilator arrests in hospital. Br Med J ; 1(6064): 808-811.

9. Horn CR, Clark TJ, Cochrane GM. Is there a circadian variation in respiratory morbidity. Br J Dis Chest 1987;81(3):248251.

10. Tuxen D. Detrimental effects of positive end-expiratory pressure during controlled mechanical ventilation of patients with severe airflow obstruction. Am Rev Respir Dis 1989;140:5-9.

11. National Asthma Education and Prevention Program. Expert Panel Report 3 (EPR-3): Guidelines for the Diagnosis and Management of Asthma-Summary Report 2007. J Allergy Clin Immunol 2007;120(5 Suppl): S94-S138.

12. Writing Committee for the American Lung Association Asthma Clinical Research Centers, Holbrook JT, Wise RA, Gold BD, Blake K, Brown ED, et al. Lansoprazole for children with poorly controlled asthma: a randomized controlled trial. JAMA 2012; 307(4):373-381. 
13. American Lung Association Asthma Clinical Research Centers, Mastronarde JG, Anthonisen NR, Castro M, Holbrook JT, Leone FT, Teague WG, et al. Efficacy of esomeprazole for treatment of poorly controlled asthma. N Engl J Med 2009;360(15):14871499.

14. Good JT Jr, Kilakowski CA, Groshong SD, Murphy JR, Martin RJ. Refractory asthma: importance of bronchoscopy to identify phenotypes and direct therapy. Chest 2012; 141(3):599-606.
15. National Heart, Lung and Blood Institute. Is the asthma action plan working? A tool for school nurse assessment. https://www. nhlbi.nih.gov/files/docs/resources/lung/asth_ act_plan_frm.pdf. Accessed March 5, 2018.

16. Global Initiative for Asthma. Global strategy for asthma management and prevention. Updated 2017. http://ginasthma.org/ 2017-gina-report-global-strategy-for-asthmamanagement-and-prevention/. Accessed July 26, 2017.
17. Bradding P, Rushby I, Scullion J, Morgan MD. As required versus regular nebulized salbutamol for the treatment of acute asthma. Eur Resp J 1999(2);13:290-294.

* Michael T Newhouse MD, invited discussant. Dr Newhouse is the chief medical officer for InspiRx.

$\dagger$ Dean R Hess PhD RRT FAARC, discussant. Dr Hess is Managing Editor of ResPIRATORY CARE. 